\title{
Meer zicht op effectieve jeugdzorginterventies via praktijkgestuurd effectonderzoek
}

\author{
Jan Willem Veerman
}

'Wat werkt bij wie?' Dat is de leidende vraag in wetenschappelijk onderzoek naar de effectiviteit van de jeugdzorg. Antwoorden op die vraag zijn niet alleen maar theoretisch interessant. Als het goed is laten praktijkfunctionarissen bij Bureau Jeugdzorg en de zorgaanbieders zich door die antwoorden leiden bij hun keuze voor de meest geschikte hulpvorm. Bovendien is de overheid serieus van plan in de toekomst alleen maar effectief gebleken interventies te gaan financieren, hiervoor zijn (en worden) verschillende erkenningscommissies in het leven geroepen. Tom van Yperen (2006) wees hier in deze rubriek in het vorige nummer van Kind en Adolescent op.

Bij het zicht krijgen op effectieve interventies staat in wetenschappelijk effectonderzoek het uitvoeren van zogeheten randomized controlled trials (RCT's) hoog in het vaandel. Hierbij krijgt een experimentele groep de interventie die men op haar effect wil onderzoeken en krijgt een controlegroep geen interventie, een placebo-interventie of een alternatieve interventie. Idealiter worden cliënten willekeurig toegewezen aan de experimentele of de controlegroep. De interventie zelf behoort helder omschreven te zijn, bij voorkeur vastgelegd in een behandelingsprotocol dat niet alleen de fasering aangeeft, maar ook wat er tijdens de verschillende sessies, bezoeken of zittingen dient te gebeuren. Eveneens moet duidelijk zijn voor wie de interventie geschikt is en voor wie niet. In het onderzoek wordt bij beide groepen een voormeting en een nameting verricht. Het effect wordt dan afgelezen aan het verschil tussen de experimentele en de controlegroep aan het eind van de interventie. Op deze manier kan gebouwd worden aan een evidence based practice waarin zicht is op de effectiviteit

Jan Willem VeermanProf. dr, Praktikon/Radboud Universiteit Nijmegen, postbus 9104, 6500 HE Nijmegen, email: jw. veerman@acsw.ru.nl van interventies waar men bij toewijzing of financiering rekening mee kan houden.

Hoewel dit op zich logisch klinkt, is dit type onderzoek in de praktijk van de jeugdzorg, daar worden tenslotte de interventies uitgevoerd, een witte raaf. Het vereist een organisatie en een controle die op de werkvloer nog lang niet haalbaar zijn. Van alle in de praktijk uitgevoerde interventies, en dat zijn er vele honderden, sommige schattingen komen zelfs op 1500 uit, is misschien één procent via een RCT onderzocht (Veerman \& Van Yperen, 2006). Dat betekent dat we strikt wetenschappelijk genomen nog niet goed weten wat er nu bij wie werkt in de jeugdzorg. Er is nog lang geen sprake van de zo vurig gewenste evidence based practice.

Om hier toch te komen kunnen in theorie twee wegen gevolgd worden:

1. Het top-down implementeren van de interventies die hun effect in een RCT hebben bewezen. Dit impliceert het transport van deze interventies naar de praktijk van alledag en onderzoek naar het welslagen van de implementatie in deze praktijk.

2. Het bottom-up onderzoeken van interventies die vandaag de dag in de praktijk worden uitgevoerd. Hiermee wordt aangesloten bij de situatie van dit moment, bij de vele interventies die dagelijks worden uitgevoerd; hier 'moet' de jeugdzorg iets mee als het gaat om zicht krijgen op effectiviteit. Dit impliceert het uitvoeren van effectonderzoek in de praktijk.

Beide wegen moeten bewandeld worden. Vanuit een wetenschappelijk perspectief wordt meestal de eerste weg aanbevolen. De eerder genoemde RCT staat hier centraal. Het idee is dat alleen op die manier maximale zekerheid ontstaat dat de onderzochte interventie effect heeft. Zo informeert de wetenschap de praktijk naar beste kunnen en draagt onderzoek bij aan het ontwikkelen van de 
gewenste evidence based practice. De definitie van effect is hier duidelijk: het verschil tussen de experimentele en de controlegroep aan het eind van de interventie. Het voordeel is de wetenschappelijk logica, die een onomstotelijk effectbewijs levert en die op het eerste gezicht ook wel aantrekkelijk is. Zo gaat het op veel meer terreinen, bijvoorbeeld bij het onderzoek naar de effectiviteit van geneesmiddelen, dus waarom ook niet op het terrein van de jeugdzorg? Het nadeel is dat de praktijk van de zorg nog niet zover is en dat het wel eens heel lang kan duren voor men zover is.

De tweede weg, beginnen bij wat er is en dat uitbouwen, wordt veel minder aanbevolen, en wordt eerder gezien als een voorwaarde om in een later stadium tot een RCT te komen. Door dit geringe aanzien is deze tweede weg nog weinig benut om wetenschappelijke kennis over effectieve interventies te verkrijgen. Het gaat hier niet zozeer om het creëren van een evidence based practice, maar om het ontwikkelen van practice based evidence (Barkham \& Mellor-Clark, 2003). De definitie van het effect is hier minder eenduidig, of op zijn minst meervoudig en de bewijsvoering is minder 'hard' dan men wellicht zou willen. Dat is wel een nadeel. Daar staat tegenover dat deze weg snel is in te slaan - vandaag nog, als het moet - en dat gaandeweg kan blijken dat de bewijzen minder 'zacht' zijn dan critici soms willen doen geloven. Anders dan bij de eerste weg vergt de tweede weg meer inbreng van en samenwerking met de praktijk van de jeugdzorg. De praktijk krijgt een sturende rol; het effectonderzoek is hier niet methodegestuurd, zoals bij de eerste weg, maar praktijkgestuurd.

In het project Zicht op Effectiviteit wordt getracht die tweede weg vorm te geven. Met behulp van een subsidie van het ministerie van Volksgezondheid, Welzijn en Sport (vws) is een stuurgroep bestaande uit Bas Bijl (PI
Research), Dries Roosma (Jeugzorg Drenthe), Herma Ooms (Collegio), Tom van Yperen (NIZw) en ondergetekende bezig die tweede weg te gaan. Voortbouwend op een eerdere definitie van Jo Hermanns (Hermanns, 1993) verstaan we onder praktijkgestuurd effectonderzoek “... onderzoek waarin onderzoekers en behandelingsfunctionarissen gezamenlijk optrekken, met het doel informatie te verzamelen waarmee het effect van het praktisch handelen van een individuele behandelingsfunctionaris, een groep van behandelingsfunctionarissen, een instelling of groep van instellingen nader verhelderd en getoetst wordt, waardoor vervolgens het werk van de betrokken behandelfunctionarissen of instellingen verbetert en tevens ten opzichte van buitenstaanders gelegitimeerd kan worden" (Veerman \& Van Yperen, 2006, p. 11). Praktijkgestuurd effectonderzoek sluit aan bij 'wat er is', namelijk bij het ontwikkelingsniveau van de te onderzoeken interventies. Het komt 'er niet bij', maar is ingebed in het hulpverlenend handelen. En het 'blijft niet liggen', want het wordt benut, zowel in het primaire proces als op managementniveau.

Bij praktijkgestuurd effectonderzoek is effectiviteit geen alles-of-niets begrip maar zijn verschillende niveaus te bereiken, die in een opklimmende reeks de treden op een ladder vormen die van laag tot hoog steeds meer zekerheid over effectiviteit van jeugdzorginterventies laten zien. Tabel 1 brengt deze effectladder in beeld (Veerman \& Van Yperen, 2006).

Bij de eerste twee niveaus gaat het erom een interventie zo goed mogelijk te beschrijven en te onderbouwen. Bij hogere niveaus gaat het er dan om daadwerkelijk te laten zien dat interventies ook gewenste uitkomsten bereiken en dat dit ook komt door de inzet van de interventie. Op het hoogste niveau komen we de vertrouwde RCT weer tegen; nu niet als startpunt van onderzoek, maar als eindpunt van een ontwikkeling waarin interventies zich steeds beter

Tabel 1 De effectladder: niveaus van effectonderzoek

\begin{tabular}{|c|c|c|}
\hline Soort effect & Omschrijving & Soorten onderzoek \\
\hline \multirow[t]{2}{*}{ 4. Werkzaam } & \multirow{2}{*}{$\begin{array}{l}\text { Als } 1 \mathrm{t} / \mathrm{m} \mathrm{3,} \mathrm{maar} \mathrm{nu} \mathrm{is} \mathrm{er} \mathrm{evidentie} \mathrm{dat} \mathrm{positieve} \mathrm{uitkomsten} \mathrm{veroorzaakt} \\
\text { worden door de interventie en is er zicht op de werkzame ingrediënten. }\end{array}$} & Experimenteel onderzoek (RCT) \\
\hline & & Herhaalde casestudies ( $N=1$ designs) \\
\hline \multirow[t]{5}{*}{ 3. Doeltreffend } & \multirow{5}{*}{$\begin{array}{l}\text { Als } 1 \text { en } 2 \text {, maar nu kan empirisch worden aangetoond dat de gestelde doelen } \\
\text { zijn bereikt, problemen afgenomen en competenties toegenomen, en } \\
\text { cliënten tevreden zijn. }\end{array}$} & Quasi-experimenteel onderzoek \\
\hline & & $\begin{array}{l}\text { Veranderingstheoretisch onderzoek } \\
\text { Normgerelateerd onderzoek }\end{array}$ \\
\hline & & Vooruitgangsonderzoek \\
\hline & & Doelrealisatieonderzoek \\
\hline & & Cliënttevredenheidsonderzoek \\
\hline \multirow[t]{2}{*}{ 2. Veelbelovend } & \multirow{2}{*}{$\begin{array}{l}\text { Als } 1 \text {, maar nu is er tevens een acceptabele interventietheorie die duidelijk } \\
\text { maakt hoe de problemen van de doelgroep zijn ontstaan en waarom de } \\
\text { interventie de beoogde uitkomsten zal bereiken. }\end{array}$} & Meta-analyse \\
\hline & & $\begin{array}{l}\text { Literatuuronderzoek } \\
\text { Kennisontlokkend onderzoek }\end{array}$ \\
\hline 1. Potentieel & $\begin{array}{l}\text { De kernelementen van een interventie (doelgroep, interventie, uitkomsten) en } \\
\text { de personele, organisatorische en materiële randvoorwaarden zijn duidelijk } \\
\text { en begrijpelijk beschreven. }\end{array}$ & $\begin{array}{l}\text { Descriptief onderzoek } \\
\text { Observationeel onderzoek } \\
\text { Documentanalyse } \\
\text { Interviews }\end{array}$ \\
\hline
\end{tabular}


kunnen bewijzen en waarbij de kwaliteit steeds meer gaat blijken.

In het project Zicht op Effectiviteit krijgt praktijkgestuurd effectonderzoek op twee manieren vorm. In de eerste plaats wordt er gewerkt aan een Bronnenboek voor praktijkgestuurd effectonderzoek in de jeugdzorg. Hierin komen uitgangspunten, voorbeelden, concrete handvatten en overstijgende kaders voor dit type onderzoek aan de orde. De conceptversie van Deel I (Uitgangspunten), II (Voorbeelden) en III (Handvatten) zijn inmiddels verschenen en gratis te downloaden van de website www. jeugdinterventies.nl of www.praktikon.nl, deel IV volgt begin komend jaar.

In de tweede plaats worden in een aantal instellingen voor jeugdzorg projecten uitgevoerd die volgens de principes van praktijkgestuurd onderzoek zijn opgezet. Deels gaat het om het versterken van bestaand onderzoek (bv. bij de 'Hulp aan Huis'-projecten in Groningen, Drenthe en Overijssel), deels gaat het om het opzetten van nieuw onderzoek in een aantal instellingen voor jeugdzorg, inclusief de geestelijke gezondheidszorg voor jeugdigen (jeugdGGZ), de justitiële zorg en de zorg voor licht verstandelijk gehandicapten. In een recent verschenen tussenrapport, eveneens te downloaden van de genoemde websites, is te lezen om welke instellingen het gaat en wordt ook verdere informatie over achtergronden en voortgang van het project gegeven.

\section{Literatuur}

Barkham, M., \& Mellor-Clark, J. (2003). Bridging evidence-based practice and practice-based evidence. Developing a rigorous and relevant knowledge for the psychological therapies. Clinical Psychology and Psychotherapy, 10, 319-327.

Hermanns, J. M. A. (1993). Tussen praktische theorieën en theoretische praktijken. In S. M. J. van Hekken, N. W. Slot, J. Stolk, \& J. W. Veerman (Red.), Pedologie tussen wetenschap en praktijk (pp. 19-30). Utrecht: De Tijdstroom.

Van Yperen, T. A. (2006). Erkenning van effectieve interventies. Kind en Adolescent, 27, 188-192.

Veerman, J. W., \& Van Yperen, T. A. (2006). Wat is praktijkgestuurd effectonderzoek? In T. A. van Yperen, \& J. W. Veerman (Red.), Zicht op effectiviteit. Bronnenboek voor praktijkgestuurd effectonderzoek in de jeugdzorg (pp. 7-19). Utrecht/Nijmegen: NIzw/Praktikon. 